\title{
A new penguin cranium from Antarctica and its implications for body size diversity during the Eocene
}

\author{
Nadia Haidr and Carolina Acosta Hospitaleche
}

With 2 figures and 1 table

\begin{abstract}
Although penguins have a very abundant fossil record in Antarctica, very few cranial elements have been found so far, and in all the cases the specimens are incomplete. We describe a new cranium of a medium-sized penguin from the late Eocene Submeseta Formation in Marambio/ Seymour Island, Antarctica. Its morphology allows us to establish a common cranial pattern for all known Eocene taxa (including South American, Antarctic and probably Oceanian species), with very different proportions between cranium and post-cranium from those of modern penguins. These Paleogene fossils exhibit a small neurocrania, extremely elongated bills, large occipital condyles, and strong cranio-mandibular articulations.
\end{abstract}

Key words: Sphenisciformes, Eocene, Seymour Island, 3D scan, anatomy, paleobiodiversity.

\section{Introduction}

Crania are among the most informative elements of the avian skeleton, not only regarding diagnostic features for systematic assignment but also from anatomical and paleobiological points of view (KSEPKA et al. 2006; Haidr \& Acosta Hospitaleche 2012; Carabajal et al. 2014). Penguins (Aves, Sphenisciformes) are more frequently preserved in the fossil record through other elements, and crania are unknown from most of the fossil species (e.g. JaDwiszcZaK 2006; Acosta Hospitaleche \& Reguero 2010; Fordyce \& Thomas 2010). For this reason, every new specimen representing cranial material provides valuable information and deserves to be reported.

The Antarctic record is represented almost exclusively by appendicular elements and vertebrae, with the exception of a few fragmentary mandibular and cranial remains, and only six crania partially preserved (JAD-
wisZCZAK 2006; KsEPKA \& BerTelli 2006; Acosta HosPitaleche \& Haidr 2011; Acosta Hospitaleche 2013). All these elements belong to large-sized penguins, with elongated bills, well-marked sagittal crests, wide temporal fossae, and large occipital condyles (JADWISZCZaK 2006; Acosta Hospitaleche \& Haidr 2011; Acosta Hospitaleche 2013).

Here, we describe a new cranium from the Submeseta Formation (formerly unit TELM7/Submeseta Allomember of the La Meseta Formation) in West Antarctica that provides new information on the diversity of penguin sizes during the Eocene in Antarctica. The material was collected within Bartonian levels in the fossiliferous locality DPV 13/84 (Acosta Hospitaleche 2013) in Marambio/Seymour Island, Antarctic Peninsula (Marenssi et al. 1998; Montes et al. 2013).

Institutional abbreviations: IAA, Instituto Antártico Argentino, San Martín, Buenos Aires Province, Argentina; MLP, Museo de La Plata, La Plata, Buenos Aires Province, Argentina. 


\section{Material and methods}

The new material was collected by members of the IAA and MLP, and it is permanently housed at the División Paleontología Vertebrados, MLP. The anatomical terminology follows that proposed by BAUMEL (1993) and supplemented by LivEZEY \& ZuSI (2006). Cranium was scanned with a NextEngine Ultra HD 3D Scanner for a better understanding of some structures. A Vernier Caliper of $0.01 \mathrm{~mm}$ of increment was used for measurements.

\section{Results - Anatomical description of the cranium MLP 12-XII-28-8}

The specimen corresponds to a cranium that partially preserves the occipital and temporal regions, part of the lamina parasphenoidalis, and the neurocranium (Fig. $1 \mathrm{~A}_{1}-1 \mathrm{~A}_{3}, 1 \mathrm{~B}_{1}-1 \mathrm{~B}_{5}$ ). It is medium sized, similar to that of the extant Spheniscus magellanicus, and smaller than all others Antarctic crania from the Eocene previously reported (Acosta Hospitaleche 2013). The only Eocene specimen that could match its size is "endocast" MLP 12-XI-1-1, whereas MLP 84-II-1-10 is too incomplete for a reliable comparison (Acosta Hospitaleche \& HAIDR 2011).

MLP 12-XII-28-8 is deformed in such a way that the dorsal part of the occipital region is rostrally inclined. It presents conspicuous cristae nuchales, the crista nuchalis sagittalis is longer than that of any other Antarctic crania (see Table 1), and the crista nuchalis transversa acquires a quadrangular design from an occipital perspective (Fig. $1 \mathrm{~A}_{1}, \mathrm{~A}_{4}, \mathrm{~B}_{1}, \mathrm{~B}_{4}$ ). The fossae temporales are cranio-caudally widened, their dorsal margins are rounded, and they are deeper at their most ventral part (Fig. 1 $\mathrm{A}_{1}, 1 \mathrm{~A}_{3}, 1 \mathrm{~B}_{1}, 1 \mathrm{~B}_{3}$ ). Inside each fossa, and over the crista nuchalis occipitalis, appears a depression with a small foramen. The foramen placed over the right margin is clearly connected with the foramen rami occipitalis arteriae ophthalmicae externae (Fig. $\left.1 \mathrm{~B}_{1}, 1 \mathrm{~B}_{3}, 1 \mathrm{~B}_{4}\right)$.

The foramen magnum is notably large and oval, with the dorsal margin smoothly rounded. The condylus occipitalis, also large, is laterally widened and kidney-shaped (Fig. 1 $\mathrm{A}_{4}, 1 \mathrm{~B}_{4}$ ). The prominentia cerebellaris does not exhibit any peculiarity and is prominent like those of the other Eocene fossils and modern species. On each side of the prominentia cerebellaris the foramen vena occipitalis externae opens on an enlarged groove. This groove is more marked on the right side (Fig. 1 $\left.1 \mathrm{~A}_{4}, 1 \mathrm{~B}_{4}\right)$. The foramen rami occipita- lis arteriae ophthalmicae externae is small and only observable on the right side. It continues on a groove that connects with the foramen placed on the nuchal margin of the fossa temporalis. The processus paroccipitales are broken, leaving exposed the recessus tympanicus caudalis. Ventrolateral to this recessus there is an eroded fossa parabasalis lacking visible foramina (Figs. $1 \mathrm{~A}_{4}, 1 \mathrm{~B}_{4}, 2$ ).

In lateral view (Fig. $1 \mathrm{~A}_{3}, 1 \mathrm{~B}_{3}$ ), aside from the temporal fossa, part of the processus zygomaticus is preserved. The articulation area with the quadrate is partially broken, only the cotyla quadratica otici remains complete, which is circular shaped. Ventral to this cotyla, there is the caudal remaining of the cavum tympanicum, with the foramen pneumaticum caudale caudally visible, and what might have been the fenestra vestibuli (f. ovalis) also present (Fig. 2A).

In ventral view (Fig. $1 \mathrm{~A}_{2}, 1 \mathrm{~B}_{2}$ ), the fossa subcondylaris is heart shaped, with a central crest, and its width is equal to half of the condyle width. The flat lamina parasphenoidalis is partially preserved and located almost at the same level as the condylus occipitalis regarding its ventral projection. The processuum mediales parasphenoidales are incomplete; however, they look more robust than those of modern forms and appear cranio-caudally elongated. These processes are also informative with respect to the size and orientation of the processus medialis of the mandible, with which they articulate (see Bock 1960).

In frontal view (Fig. 1 $\mathrm{A}_{5}, 1 \mathrm{~B}_{5}$ ), some internal features are visible due to fragmentation of the anterior portion of the skull. The tuba auditiva and the canalis caroticus cranialis (c.c.c.) are visible ventrally in both right and left sides, running parallel to each other (the tuba auditiva covers the c.c.c. on a complete skull of Spheniscus magellanicus). Both structures appear wider than those of the extant forms (Figs. 1 $\mathrm{A}_{5}, 1 \mathrm{~B}_{5}$, $\left.1 \mathrm{C}_{5}, 2\right)$. The caudalmost portion of the foramen nervi maxillomandibularis is visible over the lateral margin of the broken skull wall, dorsal to the c.c.c. and ventral to the fonticulus laterosphenoproöticus (new term from Livezey and Zusi 2006, described for Aptenodytes patagonicus and observed also in the comparative material of Spheniscus magellanicus) (Figs. $1 \mathrm{~A}_{5}, 1 \mathrm{~B}_{5}, 1 \mathrm{C}_{5}, 2$ ).

\section{Discussion and final remarks}

We know that the taxonomic and morphological diversity of fossil penguins in the past was higher than it is today (JadwisZCZAK 2006; Acosta HospitaleChe 2010). 


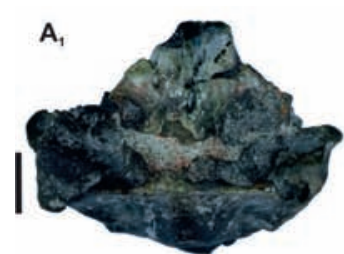

B,

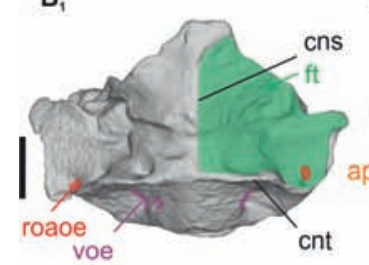

c,

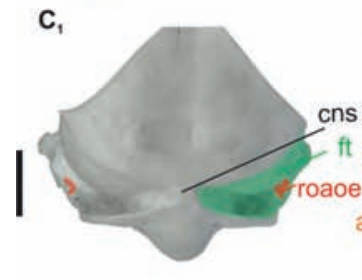

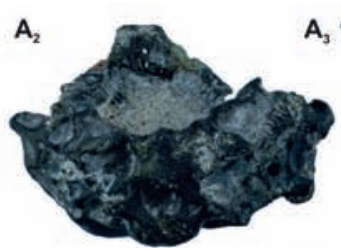

A
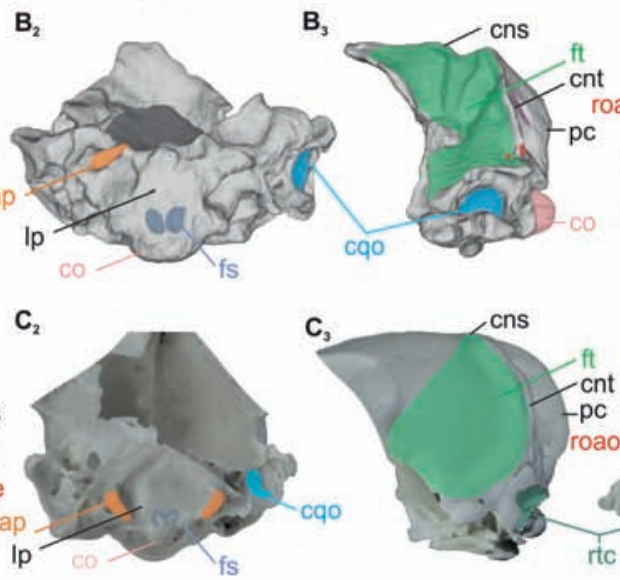

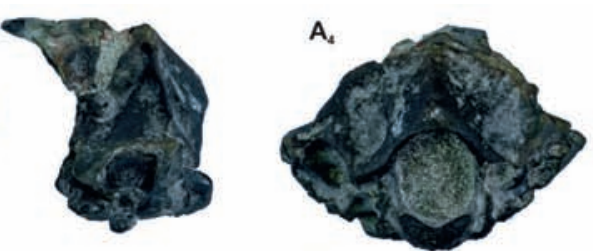

$\mathrm{B}_{4}$

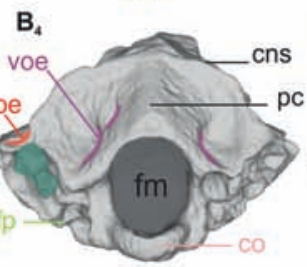

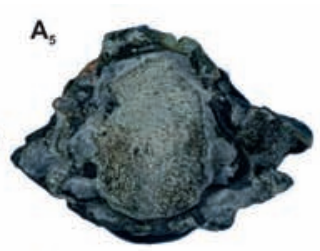

$\mathbf{B}_{5}$

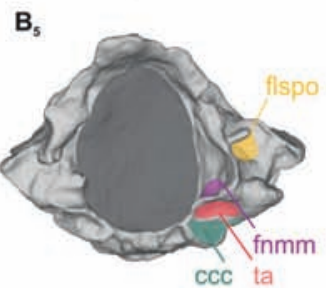

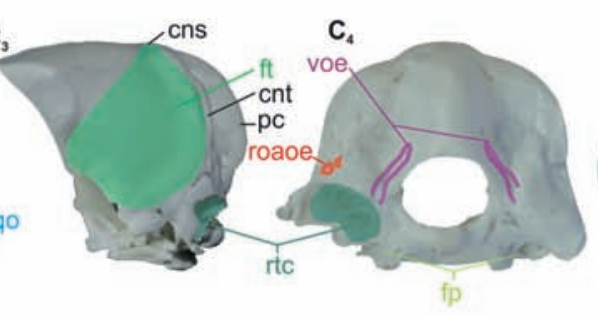

$C_{5}$

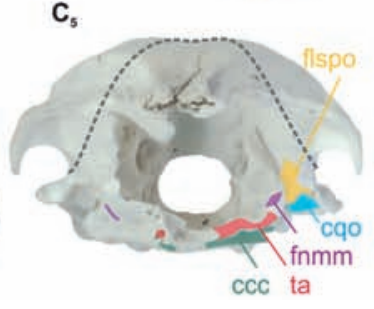

Fig. 1. A - Eocene cranium MLP 12-XII-28-8. B - 3D scans of the fossil. C - Cranium of recent Spheniscus magellanicus used for comparison. A1, B1, C1: Material set in dorsal views. A2, B2, C2: Ventral views. A3, B3, C3: Lateral views. A4, B4, C4: Occipital views. A5, B5, C5: Frontal views. Abbreviations: ap, processus medialis parasphenoidalis; cns, crista nuchalis sagittalis; cnt, crista nuchalis transversa; co, condylus occipitalis; cqo, cotyla quadratica otici; fm, foramen magnum; flspo, fonticulus laterosphenoproöticus; fnmm, foramen nervi maxillomandibularis; fs, fossa subcondylaris; ft, fossa temporalis; $\mathrm{lp}$, lamina parasphenoidalis; pc, prominentia cerebellaris; roaoe, foramen rami occipitalis arteriae ophthalmicae externae; rtc, recessus tympanicus caudalis; voe, foramen vena occipitalis externae. Scale bar: $10 \mathrm{~mm}$.
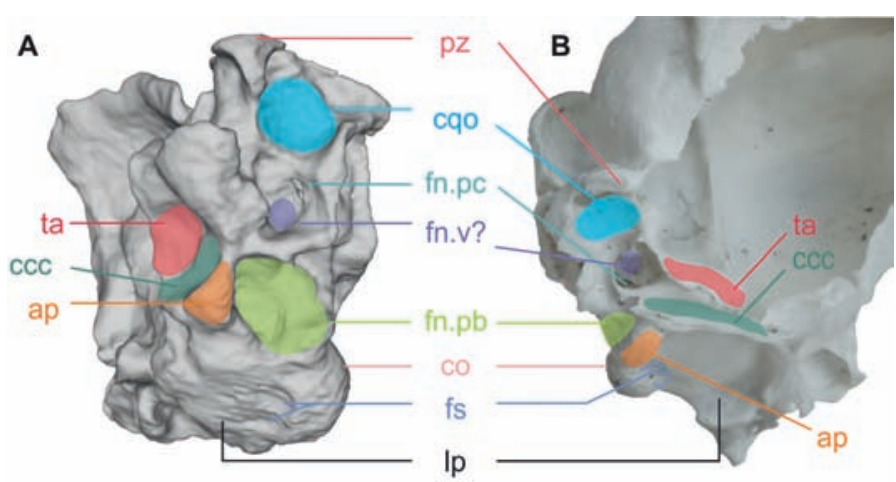

Fig. 2. A - Ventro-lateral view of a 3D scan of the fossil Eocene cranium MLP 12-XII-28-8. B - Ventro-lateral view of a cranium of Recent Spheniscus magellanicus. Abbreviations: ap, processus medialis parasphenoidalis; ccc, canalis caroticus cranialis; co, condylus occipitalis; cqo, cotyla quadratica otici; fn.pb, fossa parabasalis; fn.pc, foramen pneumaticum caudale; fn.v?, fenestra vestibuli?; fs, fossa subcondylaris; lp, lamina parasphenoidalis; pz, processus zygomaticus; ta, tuba auditiva. Images are not to scale.

However, and despite the number of recognized species from the Eocene of Antarctica (see JADWISZCZAK 2006; TAmbussi \& Acosta Hospitaleche 2007; Acosta
HosPiTALECHE et al. 2017), it is clear that morphological diversity is not completely understood. Since almost all of these fossils were found isolated, the proportions 
Table 1. Comparison of cranial measurements of Eocene Antarctic penguins [values in millimeters].

\begin{tabular}{l|c|c|c|c|c|c}
\hline & & MLP & MLP & MLP & MLP & MLP \\
& & $12-X I I-28-8$ & $12-I-20-2$ & $12-I-20-1$ & $84-I I-1-10$ & $12-X I-1-1$ \\
\hline Sagittal crest & & 7.9 & 7.6 & 10 & - \\
\hline Foramen magnum & height & 14.7 & 18.1 & - & - & 14.8 \\
\hline & width & 12.6 & 13.1 & 13.8 & 10.7 & 11.9 \\
\hline & height & 4.2 & - & 6.8 & 8.0 & - \\
\hline Occipital condyle & width & 12.5 & - & 12.6 & 10 & - \\
\hline
\end{tabular}

among the different elements of the skeleton are still unknown for the majority of the species. This is the case of the crania, which have not been found articulated with the postcranium in any of the cases.

MLP 12-XII-28-8 introduces a new element for the analysis of these faunas, the presence of medium sized crania. More complete and articulated materials will permit this diversity to be systematically ordered.

MLP 12-XII-28-8 allows us to establish a morphological pattern that, as far as we can analyze, is common to all Eocene penguins, including Antarctic (see anatomic detail in Acosta Hospitaleche 2013), South American (e.g., KSEPKA et al. 2008) and probably Oceanian specimens. The proportions of the neurocranium with respect to the bill and probably also with respect to the postcranial skeleton would have been very different from those developed towards the Neogene and today.

Although the findings are still insufficient to have a clear picture in this regard, we can predict some general characters for Eocene penguins with respect to the modern forms. Their bills would have been markedly elongated, constituting the reason for which skulls were typically rostro-caudally stretched. On the contrary, their neurocrania would have been smaller relative to the postcranial skeleton, but with a condylus occipitalis proportionally larger and strong cranio-mandibular articulations.

\section{Acknowledgements}

To the Instituto Antártico Argentino for field support. GuILLERMO LÓPEZ collected the material during field trip works, and the rest of the Heidi group, Javier N. Gelfo, SERgio Santillana and Marcelo Reguero collaborate in the field. Vanesa De Pietri and Piotr Jadwiszczak for improving the manuscript.

Author contributions: $\mathrm{CAH}$ and $\mathrm{NH}$ equally contribute to the description of the finding, figures design and develop- ment, writing the manuscript, and the critical revision. Both authors approved the submitted version of the article.

\section{References}

Acosta Hospitaleche, C. (2013): New crania from Seymour Island (Antarctica) shed light on anatomy of Eocene penguins. - Polish Polar Research, 34: 397-412.

Acosta Hospitaleche, C. \& Haidr, N. (2011): Penguin cranial remains from the Eocene La Meseta Formation, Isla Marambio (Seymour Island), Antarctic Peninsula. - Antarctic Science, 23: 369-378.

Acosta Hospitaleche, C.A. \& Reguero, M. (2010): First articulated skeleton of Palaeeudyptes gunnari from the late Eocene of Isla Marambio (Seymour Island), Antarctica. - Antarctic Science, 22: 289-298.

Acosta Hospitaleche, C., Reguero, M. \& Santillana, S. (2017): Aprosdokitos mikrotero gen. et sp. nov., the tiniest Sphenisciformes that lived in Antarctica during the Paleogene. - Neues Jahrbuch für Geologie und Paläontologie, Abhandlungen, 283: 25-34.

BAumel, J.J. (1993): Handbook of avian anatomy: nomina anatomica avium. - Cambridge, MA (Cambridge University Press, Publications of the Nuttall Ornithological Club).

Bock, W.J. (1960): The palatine process of the premaxilla in the Passeres. - Bulletin of the Museum of Comparative Zoology, 122: 361-488.

Carabajal, A.P., Acosta Hospitaleche, C. \& Yury Yáñez, R.E. (2014): Endocranial morphology of Pygoscelis calderensis (Aves, Spheniscidae) from the Neogene of Chile and remarks on brain morphology in modern Pygoscelis. - Historical Biology, 27: 571-582.

Fordyce, R.E. \& Thomas, D.B. (2011): Kaiika maxwelli, a new Early Eocene archaic penguin (Sphenisciformes, Aves) from Waihao Valley, South Canterbury, New Zealand. - New Zealand Journal of Geology and Geophysics, 54: 43-51.

Haidr, N. \& Acosta Hospitaleche, C.A. (2012): Feeding habits of Antarctic Eocene penguins from a morphofunctional perspective. - Neues Jahrbuch für Geologie und Paläontologie, Abhandlungen, 263: 125-131.

JADWISZCZAK, P. (2006): Eocene penguins of Seymour Island, Antarctica: Taxonomy. - Polish Polar Research, 27: 3-62. KsepKA, D.T. \& Bertelli, S. (2006): Fossil penguin (Aves: 
Sphenisciformes) cranial material from the Eocene of Seymour Island (Antarctica). - Historical Biology, 18: 389-395.

Ksepka, D.T., Clarke, J.A., DeVries, T.J. \& Urbina, M. (2008): Osteology of Icadyptes salasi, a giant penguin from the Eocene of Peru. - Journal of Anatomy, 213: 131-147.

Ksepka, D.T., Bertelli, S. \& Giannini, N.P. (2006): The phylogeny of the living and fossil Sphenisciformes (penguins). - Cladistics, 22: 412-441.

LiveZEY, B.C. \& Zusi, R.L. (2006): Phylogeny of Neornithes. - Bulletin of the Carnegie Museum of Natural History, 37: $1-544$.

Marenssi, S.A., Santillana, S.N. \& Rinaldi, C.A. (1998): Stratigraphy of the La Meseta Formation (Eocene), Marambio (Seymour) Island, Antarctica. - In: CASADío, S. (Ed.): Paleógeno de América del Sur y de la Península Antártica. - Asociación Paleontológica Argentina, Publicación Especial, 5: 137-146.

Montes, M., Nozal, F., Santillana, S., Marenssi, S. \& Olivero, E. (2013): Mapa geológico de Isla Marambio (Seymour). Antártida; escala 1:20.000 ( $1^{\mathrm{a}}$ edición). Serie Cartográfica.

Tambussi, C. \& Acosta Hospitaleche, C. (2007): Antarctic birds (Neornithes) during the Cretaceous-Eocene times. - Revista de la Asociación Geológica Argentina, 62: 604-617.
Manuscript received: September 2nd, 2017.

Revised version accepted by the Stuttgart editor: October 13th, 2017.

\section{Addresses of the authors:}

Nadia HaIdr, Instituto de Biología de Organismos Marinos, IBIOMAR-CONICET, Bvd. Brown 2915, U9120ACD, Puerto Madryn, Argentina;

e-mail: nadiahaidr@gmail.com

Carolina Acosta Hospitaleche, División Paleontología Vertebrados, Museo de La Plata, CONICET, Paseo del Bosque s/n, B1900FWA, La Plata, Argentina;

e-mail: acostacaro@fcnym.unlp.edu.ar 
